\title{
Education Status of Husband and Wife and its Influence on Acceptance of Contraception
}

\author{
Buddhi Kumar Shrestha, ${ }^{\mathrm{a}, \mathrm{c}}$ Subha Shrestha ${ }^{\mathrm{b}, \mathrm{c}}$
}

\begin{abstract}
:
Introduction: Acceptance of family planning is influenced by a variety of interrelated factors such as age at marriage, education, economic status, religion, number of living children etc. This study is an endeavor to assess the relation between education status of husband and wife and acceptance of contraception among postpartum women at Lumbini Medical College Teaching Hospital. Methods: A prospective, observational analytical study was conducted in Obstetrics and Gynecology department of Lumbini Medical College. The information on socio-demographic data, educational status of husband and wife and willingness to accept any form of contraception within the next three months was obtained by an interview, utilizing a questionnaire. Results: There were 615 postpartum ladies accompanied by their husbands who were included in the study. Mean age of wives was 25.11 years $(S D=5.36$, range 17-45) and husbands was 27.89 years $(S D=5.55$, range $20-47)$. Contraceptive acceptance was shown to increase significantly with literacy status. Illiterate husbands and wives refused to accept the contraception which was statistically significant. $(p<0.001)$

Conclusion: Contraceptive acceptance was significantly poor in illiterate wives and husbands whereas it was significantly higher in educated wives and husbands of all education levels. We feel the need of more education programs and education friendly socio-economic conditions which increases the acceptance of contraception thereby assisting family planning and population control.
\end{abstract}

Keywords: contraception • educational status • postpartum

\section{INTRODUCTION:}

An unintended pregnancy is a pregnancy that is either mistimed (i.e., they occurred earlier than desired) or unwanted (i.e. they occurred when no children, or no more children were desired) at the time of conception. In Nepal, most of them have been occurring due to non-use of family planning method or because of contraception failure. ${ }^{1}$ Contraceptive counseling has become an integral part of antenatal and postpartum programs as pregnant and postpartum women are generally highly motivated towards

\footnotetext{
a - Assistant Professor

b - Lecturer

c- Department of Obstetrics and Gynecology

Lumbini Medical College Teaching Hospital

Corresponding Author:

Dr. Buddhi Kumar Shrestha

e-mail: drbuddhi205@gmail.com
}

How to cite this article:

Shrestha BK, Shrestha S. Education status of husband and wife and its influence on acceptance of contraception. Journal of Lumbini Medical College, 2015;3(1):5-7. doi: 10.22502/jlmc.v3i1.60. controlling their fertility either in birth spacing or in stopping their fertility altogether. The time during pregnancy and that immediately after delivery may be the only time for the obstetrician to connect with women who are poorly motivated to obtain routine healthcare, best described as 'crisis-oriented'. 2,3 The postpartum period is potentially an ideal time to begin contraception as women are more strongly motivated to do so at this time, which also has the advantage of being convenient for both patients and health-care providers. ${ }^{4}$

Acceptance of family planning is influenced by a variety of interrelated factors such as age at marriage, education, economic status, religion, number of living children etc. Education status of husband and wife may affect the acceptance of contraception. Therefore, we aim to assess the educational status of the couple delivered at Lumbini Medical College Teaching Hospital (LMCTH) and to know its impact on acceptance of contraceptives during postpartum period. 


\section{METHODS:}

This was a prospective, observational analytical study conducted from October 2014 to March 2015 at Lumbini Medical College Teaching Hospital. All postpartum ladies of child bearing age (18-45 years) in the postnatal ward of department of Obstetrics and Gynecology were included in the study. Ladies who were not accompanied by husband at the time of delivery, had a mental disability and refused to be involved in the study were excluded.

The information on socio-demographic data, educational status of husband and wife and willingness to accept any form of contraception within the next three months was obtained by an interview, utilizing a questionnaire. The questionnaire was pretested by a panel of experts working in the respective fields. Data were collected in Microsoft Excel 2007 and analyzed in SPSS 21. Descriptive and inferential statistics were applied and a $P$ value $<.05$ was considered significant.

\section{RESULTS:}

Total deliveries at LMCTH during study period were 1052 and out of those 615 couples who met the inclusion criteria were included in the study. Mean age of wives was 25.11 years $(S D=5.36$, range $17-45)$ and husbands was 27.89 years $(S D=5.55$, range 20-47). Literacy and educational status of husbands and wives is presented in Table 1 and 2. Chi-square test of independence in Table 1 shows that there is no difference in literacy status in different gender. Chi-square goodness of fit test in Table 2 shows that the level of education is comparable across all levels in husbands and wives.

Table 1: Literacy status of Husbands and Wives

\begin{tabular}{lccc}
\hline & $\begin{array}{c}\text { Illiterate } \\
\text { n (\%) }\end{array}$ & $\begin{array}{c}\text { Educated } \\
\text { n (\%) }\end{array}$ & \\
\hline Husbands & $127(20.6 \%)$ & $488(79.4 \%)$ & $X^{2}=2.67, d f=1$ \\
Wives & $152(24.7 \%)$ & $463(75.3 \%)$ & $p=.1$ \\
\hline
\end{tabular}

Table 2: Education status of Husbands and Wives according to level of education

\begin{tabular}{cccc}
\hline $\begin{array}{c}\text { Education } \\
\text { status }\end{array}$ & $\begin{array}{c}\text { Husbands } \\
n\end{array}$ & $\begin{array}{c}\text { Wives } \\
n\end{array}$ & \\
\hline Illiterate $(n=279)$ & 127 & 152 & $\begin{array}{c}X^{2}=2.24, d f=1, \\
p=.13\end{array}$ \\
$\begin{array}{c}\text { Primary level } \\
(n=360)\end{array}$ & 195 & 165 & $\begin{array}{c}X^{2}=2.5, d f=1, \\
p=.11\end{array}$ \\
$\begin{array}{c}\text { High school level } \\
(n=543)\end{array}$ & 266 & 277 & $\begin{array}{c}X^{2}=.22, d f=1, \\
p=.64\end{array}$ \\
$\begin{array}{c}\text { Graduate level } \\
(n=48)\end{array}$ & 27 & 21 & $\begin{array}{c}X^{2}=.75, d f=1, \\
p=.39\end{array}$ \\
\hline
\end{tabular}

Acceptance of contraception in wives according to educational level is shown in Table 3. Chisquare test of goodness of fit shows that illiterate wives refused to accept the contraception which was statistically significant. On the other hand, educated wives of all levels accepted some form of contraception, which was again statistically significant.

\begin{tabular}{lccc} 
Table 3: Education status and acceptance of contraception in wives \\
\hline $\begin{array}{c}\text { Education } \\
\text { status }\end{array}$ & Accepted & $\begin{array}{c}\text { Not } \\
\text { accepted }\end{array}$ \\
\hline Illiterate $(n=152)$ & 22 & 130 & $\begin{array}{c}X^{2}=76.74 \\
d f=1, p<.001\end{array}$ \\
Primary level $(n=165)$ & 97 & 68 & $\begin{array}{c}X^{2}=5.1, d f=1 \\
p=.02\end{array}$ \\
High school $(n=277)$ & 215 & 62 & $\begin{array}{c}X^{2}=84.5 \\
d f=1, p<.001 \\
X^{2}=5.76 \\
d f=1, p=.02\end{array}$ \\
\hline Graduate $(n=21)$ & 16 & 5 &
\end{tabular}

Acceptance of contraception in husbands according to educational level is shown in Table 4 . Chi-square test of goodness of fit shows that illiterate husbands refused to accept the contraception which was statistically significant. On the other hand, educated husbands of all levels accepted some form of contraception, which was again statistically significant.

Table 4: Education status and acceptance of contraception in husbands

\begin{tabular}{lccl}
\hline \multicolumn{1}{c}{ Education } & Accepted & $\begin{array}{c}\text { Not } \\
\text { accepted }\end{array}$ \\
\hline Illiterate $(n=127)$ & 20 & 107 & $\begin{array}{l}X 2=59.6 \\
d f=1, p<.001\end{array}$ \\
Primary level $(n=195)$ & 126 & 69 & $\begin{array}{l}X 2=16.67 \\
d f=1, p<.001\end{array}$ \\
High school $(n=266)$ & 237 & 29 & $\begin{array}{l}X 2=162.65 \\
d f=1, p<.001\end{array}$ \\
Graduate $(n=27)$ & 22 & 5 & $\begin{array}{l}X 2=10.7 \\
d f=1, p=.001\end{array}$ \\
\hline
\end{tabular}

\section{DISCUSSION:}

Family planning is a basic human right. All individuals have right to access, choice, and benefits of the scientific progress in the selection of family planning method.

This study examined how education status affects approval of contraception among couples. It was found that the education status and the level of education of both husband and wife were positively associated with the use of contraception by couples. In family planning, the programs usually 
aim women as the target group and ignore the role of men. In traditional society where decisions are largely taken by men, they should be actively involved in reproductive decision of the couple. ${ }^{5}$ This study revealed that the education status and level of the husband is associated with acceptance of any kinds of contraceptives. Husband approval of family planning is also important to those women who intend to use modern contraceptives in future. ${ }^{6}$ In our study, we found that use of contraception was more in literate and educated group compared to illiterate group. We also found that it was easier to explain the advantages and disadvantages of different contraceptive methods amongst educated group. Most of the couples with higher education could choose contraceptive as per their convenience as in a study by Radulovic et al., in which the couples with higher education gave the best definition of contraception and also could choose contraceptive of their choice. ${ }^{7}$ This study also revealed that the women with primary education use less protection from unwanted pregnancy than women with secondary and higher degree which is similar to the finding in our study. While interviewing the couples, we realized that education plays a very important

\section{REFERENCES:}

1. Center for research on environment health and population activities. Management of abortion related complications in hospitals of nepal - a situation analysis. CREHPA, Kathmandu; 2000

2. Mohamed SA, Kamel MA, Shaaban OM, Salem HT. Acceptability for the use of postpartum intrauterine contraceptive devices - Assiut experience. Med Princ Pract. 2003 Jul-Sep;12(3):170-5.

3. Darnel L, Jones MD, David R, Helbert MD. Postpartum contraception. Clin Med. 1975;82:20-2.

4. Xu JX, Reusche C, Burdan A. Immediate post-placental insertion of intrauterine device: A review of Chinese and world experiences. Adv Contracept. 1994;10:71-82. role in the acceptance of different family planning method. As correctly stated by World Bank Agenda 21 , we found that educated women were more independent in making decision regarding family planning issues. ${ }^{8}$

Issues affecting women such as education and access to health care have significant consequences on sustainable development therefore educating couples may play an important role in determining overall levels of reproductive health.

\section{CONCLUSION:}

Contraceptive acceptance was significantly poor in illiterate wives and husbands whereas it was significantly higher in educated wives and husbands of all education levels. We feel the need of more education programs and education friendly socioeconomic conditions which increases the acceptance contraception which would help in family planning and population control.

\section{Conflict of interest declared: None}

Financial interest: None
5. Ha B, Jayasuriya R, Owen N. Predictors of men's acceptance of modern contraceptive practice: study in rural Vietnam. Health Education and Behavior. 2005;32(6):738-50.

6. Shahjahan MD, Mumu SJ, Afroz A, Chowdhury HA, Kabir R, Ahmed K. Determinants of male participation in reproductive healthcare services: a cross-sectional study. Reprod Health. 2013;10(1):27.

7. Radulovic O, Sagric C, Visnjic A. The Influence of education level on family planning. Medicine and Biology. 2006;13(1):58-64

8. World Bank. Advancing Sustainable Development: The World Bank and Agenda 21. Rio Earth Summit; 1997. 